\title{
The Forming of Students' Intellectual Tolerance: Theoretical Study and Implementation
}

\author{
M. Rodionov ${ }^{1}$, Z. Dedovets ${ }^{2}$ \\ Penza State University ${ }^{1}$, Penza, Russia \\ The University of the West Indies ${ }^{2}$, Trinidad and Tobago
}

\begin{abstract}
This study examines the possibility of strengthen the capacity of developing the potential mathematical education. The high level of intelligence is determined as the willingness of the individual to use new approaches to an object of study. Therefore the study of the intellectual tolerance, which manifests itself in a variety of teaching situations, is important.

Intellectual tolerance can be successfully formed and developed by the teaching of basic and elective mathematics courses. For these courses a teacher should select and optimize specific pedagogical strategies and teaching methods. As a result the teacher will make students aware to other visions of the perception of a fact or phenomenon under study. These strategies: the breaking of stereotypes of thinking, the development of the ability to modify activity in changing situations, the development of the ability to find a simple, unexpected and elegant solution, all increase the efficiency of students' learning. Following these strategies a teacher creates a convenient environment for students to be free in choosing a direction of their own research. At this stage heuristic conversation, "brainstorming", a prolonged self-study, students' research projects should be applied by a teacher. In this case students must also use logical reasoning and heuristics procedures. Our research justifies the basics of pedagogical strategies and teaching methods related to individual and age features of students, which affect the forming and developing of the intellectual tolerance in the mathematics education process.
\end{abstract}

\section{Introduction}

Creative process in any area of intellectual activity demands the intense mental activity and imagination, attention concentration, utilization of all the knowledge and experience in order to solve a problem. But not every intellectual activity can be considered creative. Mental activity also can be just a mechanical process if it consists of algorithms based operations that are monotonously repeated.

From pedagogic standpoint students' creativity is a productive intellectual process of mastering the knowledge, cultural and spiritual wealth amassed by the Mankind. The creative thinking is a result of a productive intellectual process in a harmonious combination with the individuals' creative qualities. It should be noted that creative productive activity is assured not only by properties of intelligence or more over by one of its factors but generally is defined by quality of thinking and personal attitude towards ones' activity.

The mathematics is a main field for a personal intellectual development. Mathematics is a primary kind of intellectual activity which every person is practically engaged since the birth by manipulating with subjects of the surrounding world. Therefore purposeful process of mathematical education creates the greatest opportunity for students to acquire such intellectual skills as: generalization, analogy, comparison, ordering, classification, opposition. These skills can be easily used in bordering scientific areas as well as in a real life.

The high level of intellectual development is characterized by individuals' ability to use new methods, means and skills for problem solving. Thus integrity and completeness of thinking make different vision and different attitude towards an object of research possible. Flexible comprehension of a situation allows an individual to feel that surrounding conditions constantly change and that everyone should change with it. There are no invariably correct, "absolute" representations, both in science and reality. Therefore it is important to research intellectual tolerance which occurs in various educational situations.

Tolerant individuals can perceive the world as it is in reality. Their cognitive impressions form in accordance with objective characteristics of events. Their cognitive images are open to any unusual information. The basic parameters of a high level of tolerance are: speed of formation of associative connections; the level of the openness, ability to see an 
object in a new light; ability to switch from habitual actions to not quite habitual, from a direct course of actions to the opposite.

Insufficient expressiveness of the examined quality of intelligence points to one-sided intellectual development. Such an individual is subconsciously "closing", rejecting cognitive contacts with the contradictions of surrounding world. Such individuals' picture of the world becomes insufficiently "porous" for the alternative information. Thus the facts and the phenomena contradicting established views, as a rule, simply are not taken into consideration, ignored. The person "is closed": it ceases to be susceptible to unexpected, loses ability for creativity. According to some data such situations may exist because of the individual's subjectivity toward other cultures, ethnic and religious groups.

Meanwhile, our long-term observations of mathematics taught in Russian schools; interviews with teachers; analyses of term paper results and verbal quizzes indicate that a comprehensive modern school education does not focus its activity on the formation of alternative and flexible thinking among students. Most students do not possess a strong focus toward alternative thinking; they do not effortlessly switch to, nor apply new or unconventional approaches and methods. Students learn various approaches that often exist as isolated concepts, with no relation to each other.

As a result we may conclude that there is a need to discover processes that will potentially enhance the influence of Mathematical education in personal development. The starting point of this research is based on the assumption that a higher level of personal intellectual development is connected to individual proclivity to observe subject matter from different angles and perspectives. The ability to do so is evidence of existing intellectual tolerance in the individual.

\section{Intellectual tolerance as a subject for psychological and pedagogical research}

Various characteristics of intellectual tolerance can be found in research done by psychologists and educators. Krutetsky deeply researched the process of students' mathematical abilities development [1]. He discovered the structure of students' mathematical abilities and revealed the ways of formation of the last. According to Krutetsky this process is based not on students' memorizing the information but their active participation in it's obtaining the independent work witch develop abilities to self-training and selfdevelopment. Creative intellectual abilities are being developed as a result [3].
According to Russian psychologists flexible and broad thinking are the main components of mathematical activity. Flexibility of mind is expressed through the freedom of thought from restricting influence of problem solving methods entrenched by the previous experience, through the ability to quickly change ones' actions when the conditions change. The improvement of the mental activity in order to find the optimal ways of problem solving is the flexible minds' response to the change of the situations' conditions. The opposite to flexibility of the mind is the inertia of the mind which is the tendency to use usual thought patterns, difficulty in switching between different activity patterns and persistent repetition of the same method regardless of it leading to wrong results.

The broad thinking could be defined as an ability to use the generalized methods of actions. The said methods can be widely used in separate not typical cases. The broad thinking is characterized by the ability to grasp the whole problem without omitting important details, the ability to summarize a problem and to expand the field of usage of the problem salvation results. Therefore the broad thinking is often called the generalization thinking.

Well known psychologist Kholodnaya underscores the importance of the tolerant thinking which is closely connected to overcoming stereotypes [2]. Stereotyping is a convenient way of classification and systemization of data, a way of better understanding of the surrounding world. The quantity and quality of stereotypes depend on personal experience. Stereotypes become obvious during the interaction of students who differ in gender, age, nationality, religion and cultural development. We can say that the stereotypes make it easier for a person to percept stable realities of the surrounding world. Stereotypes become obstacles when we deal with dynamic creative processes, in our case when we try to solve mathematical research problems. Stereotypes stiffen the thinking, lead to bias and conservatism in solving new problems. They force the mind to take easy, tried paths which do not lead to a correct solution. Routine way of thinking leads to ignoring of the phenomena that contradict persons' usual views. Which have established at the person about due, simply do not take into consideration, are ignored. The student becomes "closed", looses the ability to percept unexpected events and looses creativity.

What are the practical ways of creative and tolerant thinking development?

Here is the table that presents those thinking qualities that constitute the "nucleus" of the developing potential of the school learning contents (see Table 1). 
Table 1. The components of tolerant thinking

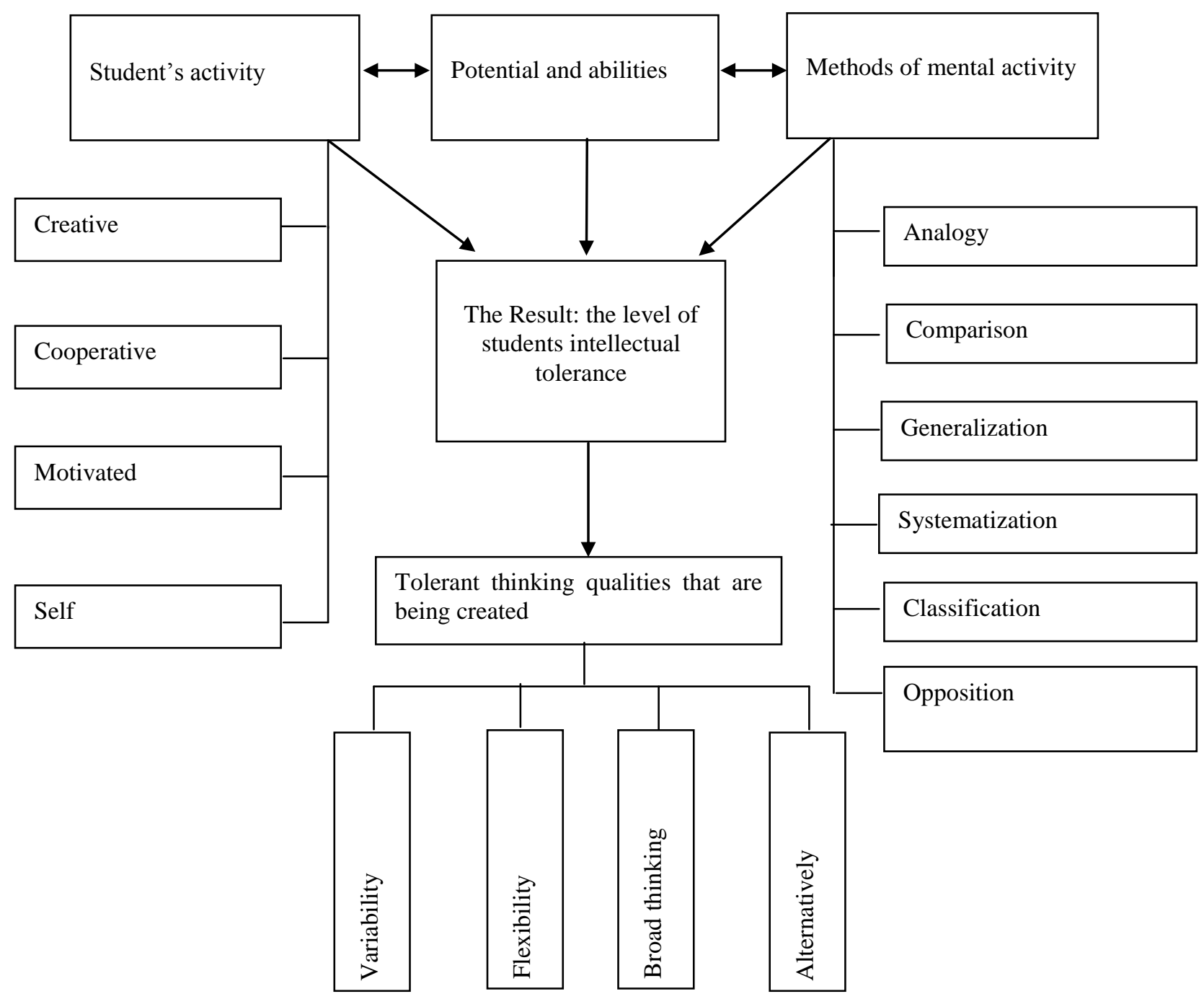

According to Table 1 the students' mental ability development is assured, on one hand, by the mutual learning creative activity of all participants of the educational process; on the other hand, by the students' experience in using such methods of thinking as analogy having the, comparison, generalization, ordering, classification, opposition. As a result of such method of training the way of thinking should acquire the following qualities: variability, flexibility, broad thinking, alternatively, tolerance.

Following the previous discussion, these qualities are shown in particular in these indicators:

1) Speed and flow of the unusual associative connections' formation; "susceptibility to problems"; "sense of novelty", ability to see an object in a new light, ability to find this object in practice (alternative way of thinking).

2) Ability to switch from habitual actions to not habitual; ability to easily alter knowledge according to the task (flexibility and variety of thinking).

3) Ability to see general things in particular ideas; ability to expand the area of the outcomes' attachment, received as a result of problem solving (width and generality of thinking).

\section{The forming of students' intellectual tolerance}

What are the practical ways of creative and tolerant thinking development? The forming of students' intellectual tolerance is not a part of contemporary school education. As a result the alternative thinking is poorly developed among the majority of students. They have hard time switching to new unusual for them actions. The ways and methods of mathematical activity are often isolated in students' mind. 
We need teachers that themselves possess the necessary quality of thinking and capable of vividly presenting to the students the limitation of their current perception in order to form in them steady aspiration to its overcoming. Also, the intellectual tolerance can successfully be formed and developed at the teaching of base and elective math courses. For these courses the teacher should choose and improve special pedagogical strategy and methods of teaching. As a result the students and the teacher together will realize the necessity of a new way of perception of the object being researched. Strategy of destruction of thinking stereotypes; developing the ability to vary the actions when the situation changes; developing skill to find the simple, unexpected and "beautiful" solution, etc. increase the students' learning efficiency $[1,3,6,7,8]$.

Natural involvement of the teacher and the student in an interesting, attractive learning process assures the formation of tolerant thinking. Creation of potentially possible worlds is an example of such a learning process. It could be: "the physical world", "the world of language", "the persons' inner world", "the world in which one of properties of space is changed" and so on. Immersion in this world allows "to have a look from the outside" at the real space corresponding this or that subject paradigm $[1,7]$.

Rather indicative example in this case is the Lobachevsky's discovery of non-Euclidean geometry when conscious change of axiomatic has led to a new perception of the surrounding space. Accordingly actualization of such a perception could serve as means of development of tolerant thinking of high school students' tolerant thinking. Thus it is necessary that examined problems, on one hand, were interesting to students and on the other contradict the child's views in order to encourage real thinking out of usual paradigms [7].

For instance, as you may know, topic "Triangles" is one of the central components of the geometric theory. In the course of this topics' presentation in the frame of schools' elective course dedicated to Hyperbolic geometry (Lobachevskian geometry), it is necessary to rely on constant comparison of well-known facts of Euclidean and Non-Euclidean geometry.

Students shall be divided into two groups. The first group prepares a report about triangles in Euclidean plane; the second group prepares a report about triangles in hyperbolic plane. Together with the teacher students try to analyze information in their reports. To summarize their discussion, they prepare a table with properties and theorems of triangles in Euclidean and Hyperbolic planes (Table 2). In the end of the class they also prepare relevant conclusions and generalizations.

Then, a further review of the same data about circles inscribed in a hyperbolic triangle and described around it, as well as its constant comparison with their "Euclidian analogues", can be offered. Therefore, overcoming of mismatches in the constructed visual representation of the logical conclusions to be accomplished demands a lot of intellectual effort from a student, what marks a new stage in his or her development.

The founder of gestalt therapy Perlz in one of his works suggested the following mind experiments: "sensation of opposite forces" (representation of the situation opposite to the initial one, comparison and understanding of the both situations; different changes of the situations and forecasting of the results of such changes); "Attention and concentration" (a concentration of attention on a visual object, singling it out from the surrounding background and to the further change of this background) [4]. The specified exercises can be utilized when studying a school mathematical material. Thus, "the sensation of opposite forces" can be formed while "developing a theme of a problem", when students, with the teacher's participation, one way or the other change conditions of a problem (drawing up and solving an opposite problem, generalization and specialization of problems, addition and exception of data and requirements of a problem, etc.) [5]. During such work and the following it discussion students form a complete mental representation of the situation around the examined problem, "the perception of a current" becomes sharper. The experiment "Attention and concentration" can be realized while working on geometrical problems when students alternately allocate key geometrical configurations, analyze them and as a result finding a way of solving the problem. At the same time the opportunity to form the sensation of "an object and a background" is created.

Focus on finding the simplest, unexpected and "beautiful" solution can be implemented already in the analysis of simple geometric, algebraic and numeric structures. School mathematical education contains a wealth of material for such analysis. Most theorems, as reflected in the contents, are examples of aesthetically appealing and often unexpected in their conclusions problematic situations. However, in order for a conclusion to appear before a student in its "sudden simplicity and charm," we have to arrange his/her independent activity directed to discovering the patterns by consolidating empirical measurements and calculations (for example, while building the heights of the triangle, the students are able to discover an unexpected for them fact of the uniqueness of the point of intersection of these heights). It is important for the teacher at this point to highlight emotionally to the students the moment of "birth" of a fruitful hypothesis 
Table 2. Properties and theorems of triangles

\begin{tabular}{|c|c|}
\hline Euclidean plane & Hyperbolic plane \\
\hline $\begin{array}{c}\text { Angles of a Euclidean triangle sum up } \\
\text { to } 180^{\circ} .\end{array}$ & The sum of the angles of a hyperbolic triangle (L-plane) is less than \\
$180^{\circ}$.
\end{tabular}

If two sides and the included angle of one triangle are congruent to two sides and the included angle of another triangle, then these two triangles are congruent.

\section{ASA Postulate:}

If two angles and the included side of one triangle are congruent to two angles and the included side of another triangle, then these two triangles are congruent.

\section{SSS Postulate:}

If three sides of one triangle are congruent to three sides of another triangle, then these two triangles are congruent.

If three angles of one triangle are respectively congruent to three angles of another triangle, then these triangles are similar.
If three angles of a hyperopic triangle are respectively congruent to three triangles of another hyperbolic triangle, then these triangles are congruent (because there are no similar triangles in Hyperbolic plane)

Special lines of a triangle are the lines that include bisectors, altitudes, medians, as well as the lines that include bisectors of exterior angles to the sides of a triangle. Intersection points of the relevant groups of the special lines are called triangle centers.

\begin{tabular}{|c|c|}
\hline \multicolumn{2}{|c|}{ The bisectors of a triangle intersect in one point. } \\
\hline \multicolumn{2}{|c|}{ The medians of a triangle intersect in one point. } \\
\hline $\begin{array}{l}\text { Altitudes of a triangle (or their } \\
\text { continuations) intersect in one point. }\end{array}$ & $\begin{array}{c}\text { Three altitudes of a hyperbolic triangle either have a common } \\
\text { intersection point, or are pair-wise parallel, or there is a unique line } \\
\text { orthogonal to all three altitudes. }\end{array}$ \\
\hline $\begin{array}{l}\text { A mid-line of a triangle is parallel to one } \\
\text { of its sides and equals half of this side. }\end{array}$ & $\begin{array}{c}\text { A mid-line of a triangle falls apart with its base, where their common } \\
\text { perpendicular goes through the middle of the base and the mid-line } \\
\text { equals less than half of the base. }\end{array}$ \\
\hline $\begin{array}{l}\text { If a line intersects one side of an acute } \\
\text { angle, it will intersect the other one as } \\
\text { well. }\end{array}$ & $\begin{array}{l}\text { Any acute angle has a line that intersects one side of the angle and } \\
\text { that is parallel to the other side of an angle. }\end{array}$ \\
\hline $\begin{array}{l}\text { Area } S \text { of the } A B C \text { triangle is } \\
\qquad S=\frac{1}{2} \text { ah }\end{array}$ & $\begin{array}{c}\sigma(\mathrm{ABC})=4 \mathrm{k}^{2} \delta(\mathrm{ABC}), \text { where } \\
\delta-\text { Defect of the ABC triangle, } \\
\delta=\pi-\mathrm{S}(\mathrm{ABC}), \mathrm{S}(\mathrm{ABC})-\text { Sum of the angular measure of the triangle, } \\
\mathrm{k}-\text { Value related to the curve of the Hyperbolic plane. }\end{array}$ \\
\hline $\begin{array}{l}\text { Angular measu } \\
\alpha=60^{\circ}\end{array}$ & $\begin{array}{l}\alpha \text { of each angle in an equiangular triangle is } \\
\qquad \alpha<60^{\circ}\end{array}$ \\
\hline \multicolumn{2}{|c|}{ Only one circle can be inscribed in one triangle. } \\
\hline Any triangle can be inscribed in a circle. & Not any triangle can be inscribed in a circle. \\
\hline
\end{tabular}


The inscribed angle is equal to one-half of its intercepted arc.
The inscribed angle is less than one-half of its intercepted arc. (through the intonation, anticipation pause or clear verbally expressed indication) in order to reinforce that feeling of discovery. A similar situation appears when the solution which initially seems very difficult is radically simplified by "unexpected" involvement of a heuristic technique.

The most perfect form of expression of a category of the surprise, that the students with already developed aesthetic taste in mathematics can comprehend, is the contrast between the simplicity of external structure of conditions of a problem and limited number of its components, on one hand, and significant, but potentially manageable challenges, overcoming of which provides its solution on the other. Students usually begin to appreciate an aesthetic appeal of such problems while acquiring an experience in a search work. The teacher should use every opportunity to draw their attention to the inner beauty of a problem which is externally expressed through fairly hard and long efforts to solve it.

Here is the simplest example of how to organize of such a work on a mathematical problem. At one of the final Planar geometry lessons it is possible to offer, among other tasks, the following problem [6, p.73].

Problem.

The area of a trapezium is equal 2, and the sum of its diagonals is equal 4. Find the height of the trapezium.

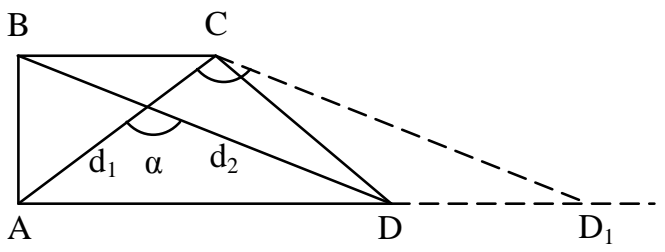

Figure 1. Trapezium ABCD

The given problem, despite that it looks simple on a surface, can be considered a rather difficult one. The main difficult task here for students is a necessity to derive the formula for the area of a trapezium through its diagonals. The task can be simplified through "reorganization" of the trapezium into a "simpler" geometrical figure - a triangle, equal this trapezium (students have already utilized this method previously during the geometry course). As a result we can get the following system of the equations:

$$
\left\{\begin{array}{l}
d_{1}+d_{2}=4 \\
d_{1} \times d_{2} \times \sin \alpha=4
\end{array}\right.
$$

From this system it is easy to derive the equation with two unknowns: $\left(4 \mathrm{~d}_{2}-\mathrm{d}_{2}^{2}\right) \times \sin \alpha=4$

It is quite possible at this moment that the students will doubt a possibility of the unique solution of the given equation as it includes two unknown values $\left(d_{2}\right.$ and $\alpha$ ).

The key moment that "unexpectedly" changes the students' perception of a situation with the given task is finding out the limitation of one of two values involved in the equation which comes from limitation of area of values of corresponding trigonometric function. Further it is possible to express $\sin \alpha$ through $\mathrm{d}_{2}$ and to make an estimation of the acquired algebraic fraction: $\sin \alpha=4 /\left(4 \mathrm{~d}_{2}-\mathrm{d}_{2}^{2}\right)<1$

The analysis of the second part of a ratio leads to two alternative cases:

1) $4 d_{2}-d_{2}^{2}<0$ (there is no solution);

2) $4 d_{2}-d_{2}^{2}>4\left(d_{2}=2\right.$, whence $\sin \alpha=1 ; \alpha=90^{\circ}$,

$\left.\mathrm{d}_{1}=2\right)$.

The further course of the solution is reduced to a finding of height of a right isosceles triangle with known sides.

Effective performance for the named approaches in the real teaching practice demands the following conditions: dialogue based teaching method, maintaining of a friendly class atmosphere, inclusion of the students to the systematic and consecutive research for information, as well as the best combination of different forms and methods in the organization of teaching activities.

\section{Conclusion}

The organization of work on development of tolerance of thinking of the child within the limits of base or elective mathematical courses requires taking into consideration not only a contextual content of such work, but also an individual and age-related peculiarities of students, their group-work skills, and also the level achieved in the subject at the given moment. However, in any case, productive transition from plans and representations of what would be possible to do to formulating real work tasks requires that a problem at hand is interesting and significant for the student and at the same time contradicts the students' way of thinking in order to induce him/her to do an educational research, instead of working in a range of the usual paradigms and views. In other words, for the teamwork of students and teachers to be effective in a described context, it is necessary to represent a teaching material in such a manner that it would naturally "absorb" both, the student and the 
teacher, as something "strange" but, at the same time, "extremely interesting" [1,2].

Principles underlying the assumed strategy are as follows: 1) alternative way of thinking, or a need to create during the studies an opportunity for alternative consideration and further comparison of different data, that is sometimes contradict, and approaches to solve problems; 2) balance between the mathematic information, aimed to create an inextricable connection within the knowledge, received previously, and inclusion of new elements that are yet not familiar to the students; 3) openness, consisting of constant orientation towards the essentially open approach of the subjects' study that allows to expand and to supplement knowledge by attracting certain external links to the analysis in the frame of the education process or outside it; 4) evaluative context that gives priority to those educational forms and methods where students themselves create ways to solve problems during their team or individual research; 5) motivation, meaning reference and further integration of contextual and sense bearing motivation factors, included to the presented topic in the field of mathematics; 6) reasonable control with an opportunity to evaluate efficiency, originality, simplicity and visualization of the made solution.

It might be important to use the elective courses that aim to destroy stereotypical thinking, to develop the ability to act differently according to changes of the situation; to familiarize variable solutions of math problems; to find different solutions depending on the type of activity. These courses should provide gradual introduction of students to free choice of the direction of the research as well as to use logic and heuristic procedures that are already familiar to students from the base math course. It is important to implement the heuristic conversation, "brain storm", long term independent work, students' research projects and so on.

We offer pedagogical solutions in a number of elective mathematical courses that we created $[5,6,7$, 8]. These courses aim at a development of thinking process and have been successfully tested in a real school environment.

\section{References}

[1] V.A. Krutetskiy, Psychology mathematical aptitudes. Moscow, Education, 1968, p. 431.

[2] M.A. Kholodnaja, Cognitive styles: About the nature of the individual mind,- 2nd ed., St. Petersburg, 2004, p. 384.

[3] V.S. Efimov Possible worlds or create practice creative thinking, Moscow, Interpracs, 1994, p. 124.
[4] F. Perls, R. Hefferime, P. Goodman, Gestalt Therapy. Excitement and Growth in the Human Personality, New York, 1951, p. 314.

[5] M. Rodionov, E. Marinina, Developing version thinking through drawing problems, Pensa, 2006, p. 95

[6] M. Rodionov Les critères de sélection du contenu des cours électifs de mathématiques. Des jeux a la creativite. Méthodes d'éducation active: Actes du Colloque organize par la FIDJIP (Fédération Internationale du Systéme JIP), l'EUROTALENT (ONG dote du statut consultative auprés du Conseil de l'Europe). Sables d'Olonnes, France, Juillet 2007, Boulogne: Editions du JIPTO, 2007, pp. 161-163.

[7] M. Rodionov, N. Titova, Creation of the "imaginary worlds" at extracurricular geometry classes, Izvestiya Vysshikh Uchebnykh Zavedenii, Volga region, Social studies, 2007, No.2, pp. 51-54.

[8] M. Rodionov, S. Velmisova Construction of Mathematical Problems by Students Themselves. American Institute of Physics (Melville, NY 11747 USA). AIP Conf. Proc. -- Issue Date: October 30, 2008, Volume 1067. pp. 221-228. http://proceedings.aip.org/proceedings.

[9] V.A. Sadovnichy, Mathematical Olympiads Problems, Moscow, MSU, 1987, p. 311 